\title{
Precision pharmacotherapy: psychiatry's future direction in preventing, diagnosing, and treating mental disorders
}

This article was published in the following Dove Press journal: Pharmacogenomics and Personalized Medicine

\author{
Andreas Menke ${ }^{1-3}$ \\ 'Department of Psychiatry, \\ Psychosomatics and Psychotherapy, \\ University Hospital of Wuerzburg, \\ Wuerzburg 97080, Germany; \\ ${ }^{2}$ Comprehensive Heart Failure Center, \\ University Hospital of Wuerzburg, \\ Wuerzburg 97080, Germany; \\ ${ }^{3}$ Interdisciplinary Center for Clinical \\ Research, University of Wuerzburg, \\ Wuerzburg 97080, Germany
}

\begin{abstract}
Mental disorders account for around one-third of disability worldwide and cause enormous personal and societal burden. Current pharmacotherapies and nonpharmacotherapies do help many patients, but there are still high rates of partial or no response, delayed effect, and unfavorable adverse effects. The current diagnostic taxonomy of mental disorders by the Diagnostic and Statistical Manual of Mental Disorders and the International Classification of Diseases relies on presenting signs and symptoms, but does not reflect evidence from neurobiological and behavioral systems. However, in the last decades, the understanding of biological mechanisms underlying mental disorders has grown and can be used for the development of precision medicine, that is, to deliver a patient-tailored individual treatment. Precision medicine may incorporate genetic variants contributing to the mental disorder and the response to pharmacotherapies, but also consider gene $\times$ environment interactions, blood-based markers, neuropsychological tests, data from electronic health records, early life adversity, stressful life events, and very proximal factors such as lifestyle, nutrition, and sport. Methods such as artificial intelligence and the underlying machine learning and deep learning approaches provide the framework to stratify patients, initiate specific tailored treatments and thus increase response rates, reduce adverse effects and medical errors. In conclusion, precision medicine uses measurable health parameters to identify individuals at risk of a mental disorder, to improve the diagnostic process and to deliver a patient-tailored treatment.
\end{abstract}

Keywords: precision medicine, personalized medicine, biomarker, mental health, depression, childhood trauma, FKBP5, machine learning

\section{Current situation and potential for precision medicine}

Mental disorders are among the most detrimental disorders worldwide. ${ }^{1}$ In Europe alone, one-third of the population suffers from mental disorders, which corresponds to 164 million persons affected. ${ }^{2}$ While over 300 psychiatric disorders are described, the three most disabling conditions in Europe were depression, dementias, and alcohol use. ${ }^{2}$ Health insurance programs reveal an increase in sick leave, early retirement, and treatment rates due to mental disorders. ${ }^{2}$ However, less than one-third of all patients receive any treatment in Europe. ${ }^{3}$ The suicide rate is higher than the annual mortality from AIDS, most forms of cancer, and homicide. ${ }^{4}$ Mental disorders also substantially increase morbidity; overall, they account for around one-third of disability worldwide and thus cause enormous personal and societal burden. ${ }^{5}$

The high personal and societal burden with increasing sick leave and early retirement reflects the insufficient treatment options currently available. Current pharma-
Correspondence: Andreas Menke Department of Psychiatry, Psychosomatics and Psychotherapy, University Hospital of Wuerzburg, Margarete-Hoeppel-Platz I, Wuerzburg 97080, Germany

Tel +49 93I 20I 76050

Email Menke_A@ukw.de 
cotherapies and nonpharmacotherapies actually do help many patients, but there are still high rates of partial or no response. In addition, the delayed onset of treatment effects and uncomfortable or even threatening adverse events further account to patients' burden. Unlike other disciplines in medicine, the diagnostic process and the choice of treatment are solely based on clinical judgment, without incorporating objective measures. Despite the amazing contributions of psychiatric research to our understanding of the etiology and pathogenesis of mental disorders, no biomarker from genomics, peripheral blood, or brain imaging has been clinically established for mental disorders. Instead, the ways patients are diagnosed and treated remained unchanged for decades. ${ }^{6}$ In addition, the current diagnostic frameworks with Diagnostic and Statistical Manual of Mental Disorders (DSM) published by the American Psychiatric Association and the International Classification of Diseases (ICD) developed by the World Health Organization rely on presenting signs and symptoms but fail to align with findings that come from genetics and clinical neuroscience. ${ }^{7,8}$

Fortunately, there is great effort to change this situation and provide individualized treatment options for each patient. Personalized and precision medicine should help matching individual patients with the most effective treatments while minimizing the risk of adverse events. ${ }^{9-11}$ Although personalized and precision medicine are often used synonymously, they technically describe two different approaches. Person- alized medicine considers sociodemographic and clinical characteristic of a patient, while precision medicine uses objective measures derived from genetics, blood-biomarkers, imaging, or neuropsychological tests to select the treatment of choice. ${ }^{10,11}$ In the past 50 years, some kind of personalization has of course taken place: physicians considered age, comedication, liver and renal functioning, comorbidities, symptoms (agitated vs nonagitated; psychotic vs nonpsychotic; sleeping problems) and patients' preferences when selecting a pharmacologic or a nonpharmacologic approach. But as stated above, this "personalization" is highly dependent on the knowledge and experience of the psychiatrist owing a trial and error in variable extend. ${ }^{12}$ The aim of precision medicine is to improve the diagnostic process and the choice of a specific treatment using genetic markers or biomarkers derived from peripheral blood, imaging, electroencephalographic measures, or neuropsychological tests (Figure 1). ${ }^{10,11,13}$ It has become increasingly clear that the diagnostic taxonomies of mental disorders by DSM or ICD are not sufficient for biomarker research, as they do not reflect relevant neurobiological and behavioral systems. Therefore, the National Institute of Mental Health started the Research Domain Criteria (RDoC) project to establish a research classification system for mental disorders that is based on neurobiological findings and observational behavior. ${ }^{7,14}$ Implementing these RDocs into biomarker research is now progressively evolving (Figure 1 ). ${ }^{15}$

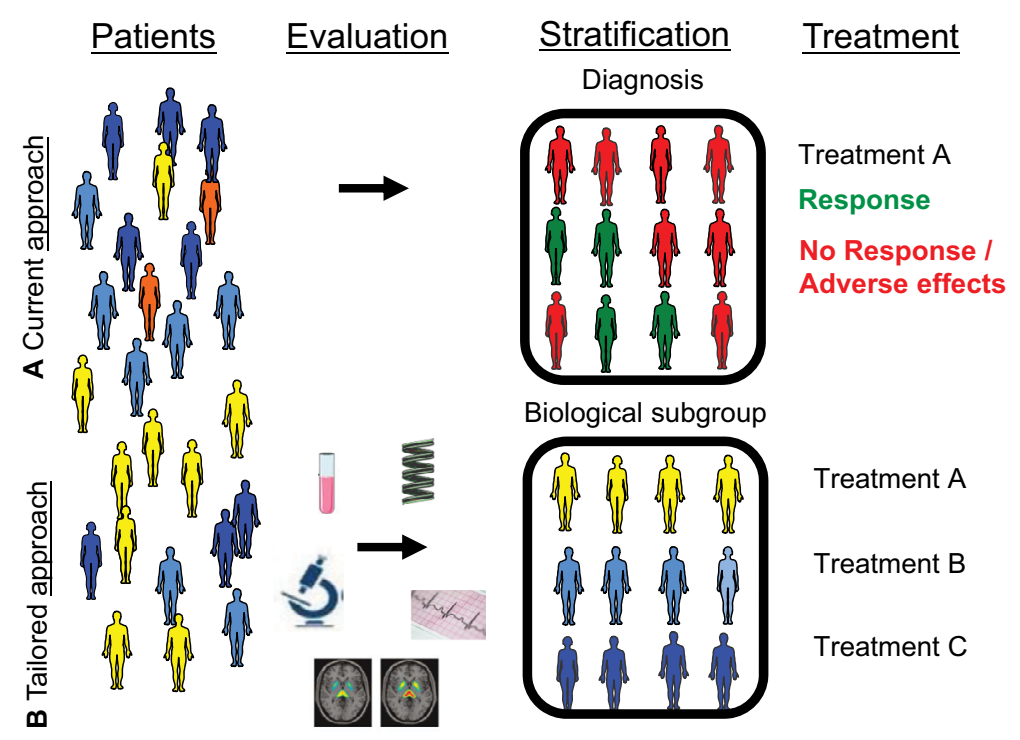

Figure I Situations of patients with mental disorders are depicted.

Notes: (A) Current situation: patients are evaluated by a clinician who stratifies the patients using the diagnostic taxonomy of DSM-5 or ICD-I0; then, first-line treatment is initiated according to the diagnosis. Treatment is usually associated with a high rate of nonresponse. (B) Future situation: precision medicine guides the tailored approach for each individual patient with a mental disorder. Patients are evaluated possibly by systems employing machine learning methods that consider genetic and other biomarkers derived from blood, neuropsychological tests, or imaging and then stratified by biological subgroups/endophenotypes. Specific treatment algorithms are initiated according to the biological subgroup.

Abbreviations: DSM, Diagnostic and Statistical Manual of Mental Disorders; ICD, International Classification of Diseases. 
In this review, several concepts of biomarker research to enable precision medicine are described. The analysis of the genetic makeup and the acknowledgement of the crucial interaction of genetic variants with environmental factors have already delivered promising predictors. Current concepts focus among others on the molecular genetic alterations of systems activated by stress, such as the stress hormone system (hypothalamic-pituitary-adrenal [HPA] axis) or the immune system. In addition, electronic devices and neuropsychological tests are described that help stratify subgroups of patients and thus help to deliver a tailored treatment. The assessment of the genetic makeup, environmental factors including lifestyle, and markers derived from the stress systems also delivers predictors to identify individuals at risk; thus, precision medicine will also set up preventive strategies to reduce the risk of developing a mental disorder. ${ }^{16}$

\section{Importance of genetic, environmental, and lifestyle factors Genetic factors}

Numerous twin studies delivered evidence of heritability of mental disorders or traits. Heritability is an estimate of the proportion of variation in a feature that can be explained by genetic differences between subjects. The heritability estimates of the major mental disorders derived from large twin studies ranges from $40 \%$ of major depressive disorder (MDD) and posttraumatic stress disorder (PTSD) to $80 \%$ of schizophrenia, bipolar disorder, and attention-deficit hyperactivity disorder (ADHD). ${ }^{17,18}$ The advances in genetics are coupled to technical advancements with array-based methods and high-throughput sequencing, but substantially rely on large-scale collaborative efforts like the Psychiatric Genomics Consortium (PGC), which have identified many common and rare genetic variants contributing to several mental disorders. ${ }^{17,19}$ Studies with small sample size failed to detect the individual genetic variants that account for much of the heritability, which was termed missing heritability. ${ }^{20}$ The genetic dissection of complex traits has been frequently reviewed and is beyond this review. ${ }^{21-23}$ For most mental disorders, genetic variants have a cumulative impact with small effect; moreover, there are environmental factors that influence gene regulation. Therefore large statistical power, that is, large sample size, is needed to overcome these drawbacks to identify associated variants. For example, the initial genome-wide association studies (GWAS) mega-analysis on MDD conducted by the PGC with 9,240 cases revealed no significant findings,${ }^{24}$ the CHARGE meta-analysis of depressive symptoms with 34,549 subjects also failed to find signifi- cant hits. ${ }^{25}$ First significant hits were delivered by Hyde et al investigating self-reported MDD in 75,607 cases; this study identified 15 significantly associated loci. ${ }^{26} \mathrm{Just}$ recently, the PGC published a GWAS meta-analysis based on 1,35,458 cases and revealed 44 independent and significant loci. ${ }^{27} \mathrm{~A}$ similar pattern could be observed analyzing schizophrenia cohorts, a mental disorder with higher heritability. A GWAS on 17,836 cases revealed five significantly associated loci; ${ }^{28}$ later a GWAS on 36,989 cases identified 108 significantly associated loci. ${ }^{29}$ Many efforts are meanwhile in place to translate these genome-wide association findings into new drug targets for mental disorders or to repurpose existing drugs for the treatment of mental disorders that were not initially developed to treat, an approach called drug repositioning. ${ }^{30,31}$ For example, the gene $H M G C R$ was identified in a GWAS on cholesterol metabolism and then has been found to be associated with the lipid-lowering response to simvastatin..$^{32,33}$ However, there are several drawbacks that hamper these approaches.

Analysis of large data sets with over 2,50,000 patients and over 7,50,000 controls revealed significant correlations of common variants between MDD and ADHD, bipolar disorder, and schizophrenia. ${ }^{34}$ In addition, significant correlations between migraine and MDD and ADHD were observed, whereas the trait neuroticism was correlated with almost every mental disorder. ${ }^{34} \mathrm{~A}$ shared molecular pathology across the major mental disorders was also observed using transcriptomic profiling from cerebral postmortem tissue of patients with MDD, bipolar disorder, autism, schizophrenia, and alcoholism. ${ }^{35}$ In this approach, a degree of shared but also distinct gene-expression perturbations across the mental disorders could be revealed. The extend of shared transcriptional dysregulation was attributed to an single nucleotide polymorphism (SNP)-based, polygenic overlap across these conditions, suggesting a substantial causal genetic component. ${ }^{35}$ Thus, the genetic variants revealed by GWAS are not necessarily associated with the investigated mental disorder but could also be related to a shared condition.

\section{Gene $\times$ environment interactions}

Next, environmental factors complicate the identification of truly associated genetic variants. In fact, the vulnerability to develop a mental disorder is crucially dependent on gene $x$ environment interactions. ${ }^{36-39}$ Environmental adverse events such as physical, sexual, or emotional childhood trauma are robustly associated with the development of mental disorders..$^{40}$ In fact, gene $\times$ environment interactions often determine the development of a mental disorder. ${ }^{41}$ However, 
it is not clear how adverse events interact with genetic and epigenetic factors to confer the vulnerability. Accumulating evidence shows that early adverse events, such as childhood trauma, mobilize fight-or-flight responses mediated by the HPA axis, by the adrenergic nervous system (ANS) and the immune system. Subsequently, it leads to an increased sensitivity of the HPA axis and to low-grade inflammation with a heightened inflammatory response to subsequent stressors. ${ }^{42,43}$ This is complemented with facilitated self-medicating behaviors like smoking, drug use, and consumption of highfat and high-sugar diets that subsequently impair the course of the mental disorder. ${ }^{44}$

In fact, there is accumulating evidence that childhood trauma is associated with significant and graded increase in inflammatory markers, such as C-reactive protein (CRP), white blood cell count, or IL- $6 .{ }^{45}$ Interestingly, these elevations cannot be explained by potential key confounders, such as low birth weight, poor health, low socioeconomic conditions, unhealthy behavior, or acute inflammation. ${ }^{45}$ Childhood trauma does also increase the reactivity to subsequent challenges; this could be observed using psychological interventions like the Trier Social Stress Test, ${ }^{46-48}$ and applying pharmacological interventions like an in-vivo glucocorticoid receptor $(\mathrm{GR})^{49}$ challenge by ingestion of dexamethasone. ${ }^{50}$ Thus, early experiences set up long-term patterns of interaction between the immune system and the brain that may be relevant for specific treatment interventions. For example, it was observed that patients with increased CRP levels showed a better response to treatment with a tricyclic antidepressant, while patients with lower CRP levels responded better to a treatment with selective serotonin reuptake inhibitors. ${ }^{51}$ Furthermore, treatment with a specific antiinflammatory agent, the TNF antagonist infliximab, did not reveal a significant improvement compared with placebo in depressed patients. However, after separating depressed patients according to CRP levels above and below $5 \mathrm{mg} / \mathrm{L}$, there was a significant better outcome in the higher CRP levels group when treated with the TNF antagonist. ${ }^{52}$ Meanwhile, systematic reviews and meta-analysis revealed beneficial effects of specific antiinflammatory agents, such as nonsteroidal anti-inflammatory drugs or anticytokine treatments. ${ }^{53,54}$ These effects may be further improved using precision medicine tests to deliver the anti-inflammatory agents to the right patients.

As described above, inflammatory pathways are closely linked to the HPA axis. At the cellular level, environmental stress promotes the release of glucocorticoids (GCs) from the adrenal glands in the systemic blood flow and thus the GCs reach every organ in the body, including the brain. GCs exert their effects via two cytoplasmatic receptors, the min- eralocorticoid receptor and the GR. They act as transcription factors and bind to certain DNA sequences, the glucocorticoid response elements (GREs), that enhance or repress gene transcription. ${ }^{55} \mathrm{GCs}$ induce transcriptional responses to stress that involve the upregulation and downregulation of numerous genes. In the transcriptional response to GCs or stress, epigenetic mechanisms are substantially involved. Environmental stress influences epigenetic mechanisms, such as DNA methylation and small and noncoding RNAs (microRNAs), and thus comprises the molecular basis of gene $\times$ environment interactions. ${ }^{56-59}$ Some genes have already been identified to be epigenetically altered by childhood trauma and significantly increase the risk to develop stress-related mental disorders. A prominent example is the FKBP5 gene that encodes the FK506 binding protein 51 (FKBP51), a heat shock protein 90 -associated co-chaperone. ${ }^{60}$ It is strongly stress responsive and modulates the sensitivity of the GR complex. Stress and GCs upregulate FKBP5 via GREs in several tissues, including peripheral blood and the brain. This upregulation activates an ultrashort feedback loop, it activates the GR, and thus induces FKBP5 expression which limits the GR activity by binding to the GR complex. ${ }^{41}$ Interestingly, this increase in FKBP5 RNA and protein is moderated by common genetic variants and specific epigenetic alterations present in subjects with childhood trauma. ${ }^{61-63}$ Beyond the cellular level, these genetic variants together with epigenetic alterations and childhood trauma were associated with structural and functional changes in several brain regions ${ }^{64-66}$ and with impaired working memory and cardiac stress reactivity. ${ }^{67}$ In this way, FKBP5 serves as an example of how individual differences in the molecular response to GC activation are associated with alterations in the stress response not only at the cellular level, but also at brain circuitry and systemic levels. ${ }^{41}$ Drugs targeting FKBP5 are currently in progress; $; 8,69$ however, they will not help all patients, but only those with a dysregulated FKBP5 functioning or GR signaling. Precision medicine approaches are necessary to detect an altered FKBP5 functioning or GR signaling to identify suitable patients for a specific FKBP5 treatment. ${ }^{50,70-72}$

\section{Environmental factors influencing vulnerability \\ Early life adversity}

Early life adversity substantially shape stress vulnerability or resilience in the first years and are thus considered as distal environmental factors. But there are also proximal environmental factors, that is, the last months before the onset of the mental disorder, which influence the risk or the course of the condition. Overall, detrimental and protective 
factors can be distinguished. Psychological stress is a major factor that significantly increase the risk to develop a stressrelated mental disorder via the activation of the HPA axis, the ANS, and inflammatory pathways. ${ }^{73}$ Not only mental disorders are impacted by stress but also cardiovascular disorders or cancer is associated with psychological stress. ${ }^{73} \mathrm{~A}$ prominent example of how psychological stress is affecting cardiovascular function was observed in 2006 during the World Cup Soccer in Germany, where cardiovascular events were significantly higher on days of matches with German participation than on the other days. ${ }^{74}$ Reasons for significant psychological stress are typically chronic conditions, such as conflicts with partner, work stress defined as low workplace control coupled with high demands, organizational injustice, financial problems, and low social support. ${ }^{73}$

\section{Healthy lifestyle: nature, nutrition, and sport}

In contrast, there are also protective factors that ameliorate the risk to develop a mental disorder, such as social support, nutrition, or exposure to natural environments. ${ }^{75,76}$ For example, walking or staying in a forest could decrease measures of depressive symptoms and hostility and increase measures of liveliness in a sample of 486 healthy volunteers. ${ }^{77}$ In addition, forest experience has robustly been shown to decrease blood pressure, pulse rate, and levels of stress hormones. ${ }^{78,79}$ Extensive observational evidence also supports the impact of nutrition on mental health; the diet quality may be a possible protective or risk factor for mental disorders. ${ }^{80-84}$ Mechanisms by which nutrition may alter the risk of mental disorders include an interaction between brain metabolism and ingested fatty acids, ${ }^{85}$ immune-system modification via immune-reactive components such as wheat gluten, ${ }^{86}$ induction of oxidative and nitrosative stress in cerebral circuits, ${ }^{87}$ and altering of the brain-gut axis and the gut microbiome. ${ }^{88}$ The traditional Mediterranean diet, characterized by a high intake of olive oil, vegetables, nuts, fruits, and cereals, a moderate intake of fish and poultry, and a low intake of sweets, red and processed meats as well as wine in moderation, ${ }^{89}$ has not only been consistently associated with lower cardiovascular risk ${ }^{90,91}$ but also with a $30 \%$ reduced risk for depression. ${ }^{92}$ A meta-analysis observed that fish consumption and fish-derived polyunsaturated fatty acids intake were associated with a lower risk of depression. ${ }^{93}$ In addition, a metaanalysis showed that the adjuvant treatment with omega-3 polyunsaturated fatty acids for MDD in combination with antidepressants and/or psychotherapy improves the overall response. ${ }^{94} \mathrm{~A}$ recent randomized controlled trial (RCT) of dietary improvement in patients with MDD as add on to antidepressants and/or psychotherapy also revealed beneficial effects. ${ }^{95}$ Interestingly, Khambadkone et al observed in a cohort of patients with mania and other mental disorders that the consumption of nitrated meat products was associated with mania, and that nitrated meats alter the behavior and brain gene expression in rats. ${ }^{96}$

One of the most beneficial factors to prevent or ameliorate mental disorders is exercise or physical activity. ${ }^{97,98}$ While the exact biological mechanisms exerted by exercise are not well understood, there is some evidence of a decrease in stress hormones such as cortisol or epinephrine as well as proinflammatory cytokines, an increase in neurotrophic factors like brain-derived neurotrophic factor and hippocampal cell proliferation. ${ }^{71,99-101}$ Exercise has preventive effects on mental disorders, for example, physical active persons have around $45 \%$ lower odds of developing depressive symptoms compared with physical inactive persons. ${ }^{97}$ In addition, several large studies observed inverse associations between depressive symptoms and physical activity. ${ }^{102}$ Moreover, RCTs and meta-analytic reviews reported beneficial effects of exercise in patients with moderate depression. ${ }^{103,104}$ Of note, exercise cannot ameliorate only MDD, there is accumulating evidence that exercise also improves job-related exhaustion, ${ }^{71}$ anxiety, ${ }^{105}$ schizophrenia, ${ }^{106}$ and dementia. ${ }^{107}$

\section{Genetic testing and electronic health data to individualize treatments}

\section{Genetic testing}

As reported above, mental disorders have a modest to high heritability; also, treatment response and the appearance of adverse effects have been shown to be genetically linked. ${ }^{108-111}$ An extensive literature covers the association of common genetic markers with the response, adverse effects, and metabolism of antidepressants and antipsychotics. ${ }^{112-114}$ Genetic variants involved in metabolism of antidepressants or antipsychotics (CYP/CYP450 isoenzymes), drug transport $(A B C B 1)$, glucocorticoid signaling ( $F K B P 5)$, and serotonin neurotransmission (SLC6A4 and HTR2A) were among those included in the first pharmacogenetic assays that have been clinically applied. ${ }^{113,115}$ Most pharmacogenetic tests focus on pharmacokinetic genes, specifically CYP2D6 and CYP2C19. ${ }^{116,117}$ Genetic variants within these genes have been repeatedly associated with patients' metabolizer phenotype $^{118,119}$ and subsequently have been included in dosing guidelines for antidepressants by expert groups such as the Clinical Pharmacogenetics Implementation Consortium. ${ }^{120}$ Genetic variants within CYP2D6 and CYP2C19 can be used 
to determine if a patient is a normal, an intermediate, a poor, or an ultrarapid metabolizer. ${ }^{118,119}$ Therefore, most of the currently commercially available pharmacogenetic tests include variants of these two genes. ${ }^{116,117} A B C B 1$ is another interesting pharmacokinetic gene that has been included in pharmacogenetic tests. It encodes the efflux pump P-glycoprotein and thus plays a pivotal role in the transfer of various drugs across the blood-brain barrier. ${ }^{121,122}$ While almost all commercially available tests include pharmacokinetic tests, only some include pharmacodynamics genes. ${ }^{116}$ Genetic variants within the promoter of the serotonin transporter gene (SLC6A4), which is a main key regulator of antidepressant mechanisms, have been repeatedly associated with treatment response to antidepressants. ${ }^{123}$ Consistent evidence also suggests an involvement of other serotonin-related genetic variants, namely 5-HT2A polymorphisms, in response to antidepressants. ${ }^{124,125}$ FKBP5 is another pharmacodynamics gene that has been associated with treatment response to antidepressants. ${ }^{60}$ Interestingly, the genetic variant that was related to a dysregulated HPA axis was also associated with a beneficial response to antidepressants. ${ }^{61}$ However, this variant is not yet routinely included in the available tests. ${ }^{117}$ The polygene approach of most of the pharmacogenetic tests is based on evidence that most antidepressants or other psychopharmacologic medications interact with multiple pharmacokinetic and pharmacodynamic pathways. ${ }^{126}$ However, current reviews state that only a small fraction with $<20 \%$ of the available pharmacogenetic tests has been empirically evaluated, and there are many gaps in the presented evidence. ${ }^{16,117}$ In addition, the cost-effectiveness still remains unclear until robust economic studies are conducted. ${ }^{127}$ Different ethnicities and the related cultural factors further complicate the usage of pharmacogenetic tests. ${ }^{128}$

The development of mental disorders is likely determined by combined effects of genetic predisposition and environmental adversity that together alter gene regulation in a way that has substantial effects on cell function and subsequently on organ systems, including brain and behavior. Thus gene expression may be considered as an integral over genetic variants predisposing to MDD and early adversity as a major environmental factor. ${ }^{129,130}$ Common approaches for gene expression analysis are quantitative reverse transcription PCR, microarrays, and RNA sequencing. In addition to the analysis of gene expression, the investigation of microRNAs (miRNA), a class of small noncoding RNAs, has been emerging rapidly, as they control gene expression by modulating translation and mRNA degradation and are involved in the stress response. ${ }^{58,131}$ Circulating miRNAs are present in peripheral blood cells and therefore are suitable to serve as predictors for diagnostic evaluations or for treatment response..$^{58,132,133}$

A multimodal approach to test the stress hormone system, that is, the HPA axis, in patients with mental disorders is the modified dexamethasone-suppression test (mDST). ${ }^{49}$ Gene expression, differential blood count, and stress hormones such as cortisol are measured before and 3 hours after GR activation in vivo with dexamethasone $1.5 \mathrm{mg}$ ingestion. In two independent cohorts, GR-activated gene expression outperformed baseline gene expression as a classifier for case and control status with a correct classification rate of $79.1 \%$ vs $41.6 \% .^{72}$ Applying the mDST in a sample with subjects affected with job-related exhaustion showed evidence for a GR hypersensitivity, comparable to patients suffering from trauma-related mental disorders. ${ }^{71,134}$ In a broader, stimulated expression quantitative trait locus approach, gene expression profiles after GR activation were combined with genomewide SNP data. This approach revealed that common genetic variants that modulate the transcriptional response to GR activation mediate the risk of MDD as well as other mental disorders. ${ }^{135}$ Moreover, these risk variants were associated with inappropriate amygdala reactivity to angry and fearful faces. ${ }^{135}$ Next, combining genome-wide DNA methylation and gene expression data before and after GR activation revealed dynamic changes in methylation of the cytosine pyrimidine ring in cytosine/guanine $(\mathrm{CpG})$ dinucleotides and transcription of gene neighboring epigenetic clock CpGs associated with aging and aging-related disorders. ${ }^{136}$ Recently, using the mDST, an increased FKBP5 gene expression could be observed together with lower cortisol levels in anxious depression, partly dependent on childhood trauma. Such a multimodal approach allows the analysis of different molecular levels of the GR-activated stress response in dependency of childhood trauma as environmental stress response to detect new targets that are crucially altered by stress and increase the risk of developing mental disorders.

\section{Electronic devices facilitating treatment selection}

In the past decades, the digital information of patients' data stored in electronic health records has grown enormously. With new tools such as machine learning algorithms, approaches are undertaken to use these vast amounts of patients' data including history, physical, laboratory, and medications. Deep learning techniques and frameworks are applied to facilitate prediction of future illness trajectories and medical outcomes. ${ }^{137-139}$ In addition, language can be also extracted from social media and analyzed with deep learning techniques to identify subjects at high risk of psychosis. ${ }^{140}$ 
Social media is a substantial part of modern smartphone use. Nearly every person uses permanently the smartphone, and via extraction of smartphone data, many studies could show the acceptability and the feasibility of this approach to monitor patients' behavior via ecological momentary assessments to predict alterations in mood and risk of the occurrence of a mental disorder. ${ }^{141}$ One example of a smartphone-based application is the Predicting Response to Depression Treatment Test (PReDicT Test) ${ }^{142}$ Experimental evidence suggests that patients suffering from MDD are more likely to interpret facial expressions of emotion more negative than matched healthy controls. ${ }^{143}$ Furthermore, it has been shown that treatment with antidepressants alters the processing of emotional information, for example, by causing depressed patients to identify facial expressions as more positive. ${ }^{144}$ Moreover, these cognitive effects of antidepressants can be detected early in the course of treatment and may predict later clinical response. ${ }^{145}$ Therefore, a clinical trial is currently conducted to assess if an electronic test measuring the accuracy of evaluating facial expressions (PReDicT Test) can be used to guide antidepressant treatment in depressed patients. ${ }^{142}$

\section{Future for diagnosis and treatment}

The enormous costs of mental disease prompt a global challenge for our societies. ${ }^{146}$ In contrast to several other severe medical conditions, such as heart disease or cancer, ${ }^{147}$ mortality has not decreased for any mental disorder, and the prevalence rates are similarly unchanged. ${ }^{148}$ Moreover, current drug treatment options are successful only in about half of the patients, ${ }^{149}$ and similar considerations apply to nonpharmacologic treatment options such as psychotherapy. ${ }^{150}$ There are many reasons for this unfavorable condition; the brain is the most complex organ in the body, and mental disorders involve highly complex interactions of environment, experience, and genetic factors. ${ }^{7}$ Several studies showed that specific drugs can be successful in a certain patient and unsuccessful in another patient, both labeled with the identical diagnosis. ${ }^{151}$ Furthermore, antidepressants are used to treat not only MDD but also a wide variety of anxiety, mood, or other mental disorders. For example, a patient diagnosed with schizophrenia may also suffer from a depressive syndrome and thus would benefit from an antidepressive medication. Likewise, there is accumulating evidence showing that risk alleles are partly shared between mental disorders, ${ }^{152}$ and the other way round, different sets of risk alleles may lead to the same mental disorder. ${ }^{153}$ To improve the current situation and to facilitate individualized treatment, also called precision medicine, several proof-of-concept studies have already gathered accumulating evidence from blood-based biomarker, genetic variants, and ambulatory assessments to neuroimaging, reviewed in excellent articles. ${ }^{9,151,154-160}$ But still no patient-tailored treatment has arrived in the clinical setting. As the traditional taxonomy of mental disorders does not reflect the underlying biological mechanisms as described above, the new era of evidence-based psychiatry tailored to single patients uses the RDoC concept that spans diagnostic boundaries integrating genetic signatures, neuropsychological tests, brain measures, and self-reports. ${ }^{7,8,14}$

Three areas of clinical application of precision medicine are important in the field of mental health: 1) prediction of therapeutic response and side effects; for example, who will respond to the first-line treatment, or to the second-line treatment, or will be treatment resistant after all?; 2) supporting differential diagnosis, for example, in the distinguishing unipolar and bipolar depressed patients without the first manic episode would have distinct therapeutic consequences with adding a mood stabilizer and preventing a manic episode; and 3) detection of the individual risk to develop a mental disorder, which can be relevant for soldiers who have an increased risk to develop PTSD or patients with a prodrome of schizophrenia, allowing preventive measure in early stages or even before the onset of the mental disorder. ${ }^{161}$ Classical statistical concepts (ie, null-hypothesis testing vs alternative hypothesis) have struggled in dealing with objectively measureable endophenotypes derived from huge datasets and to extrapolate patterns from one set of data to another set. ${ }^{162}$ While these tests often determine differences between affected vs healthy subjects or treatment vs placebo group, they do not help in finding a differential diagnosis or the right treatment among numerous competing treatment groups. ${ }^{162}$ In contrast, machine learning uncovers general concepts underlying a series of observations without explicit instructions. ${ }^{161,162}$ Machine learning concepts include supervised methods such as neural-network algorithms and support vector machines to identify outcome predictors; and unsupervised methods, such as algorithms for dimensionality reduction and data clustering to reveal biological subgroups in patients. ${ }^{162}$ New predictors derived from these procedures are extrapolated to future data samples via cross-validation; first, the predictors are identified in training datasets, and in a second step the generalization performance is evaluated on test data, also called out of sample. ${ }^{163}$ Especially, in mental disorders with complex possible treatment combinations, differential diagnosis and disease trajectories denoting more than two categories, multiclass learning and multitask learning approaches, are applied. ${ }^{164}$ For example, Kessler et al used some of these machine learning concepts in a prospective national household sample of over 1,000 respondents with 
lifetime MDD and could generate a risk stratification for subsequent hospitalization or suicide attempt based on baseline self-reports. ${ }^{165}$ Deep learning, another paradigm of machine learning, has meanwhile been successful in various artificial intelligence research areas such as language processing, speech recognition, self-driving cars, or computer vision. ${ }^{166}$ Artificial intelligence systems are supposed to acquire data, combine data, and then perform tasks and support decisions independent of humans. ${ }^{167}$ Deep learning takes advantage of the increased amounts of data and computer power which enables multilayer feed-forward networks, that is, artificial neural networks with many layers of nonlinear processing units for learning data representations. ${ }^{166}$ For example, Lin et al used a deep learning approach to find treatment predictors from a set of genetic variants (single nucleotide polymorhisms, SNPs) and clinical factors such as age, sex, baseline severity of MDD, suicide attempts, previous depressive episodes, and marital status. ${ }^{168}$ A multilayer feed-forward neural network containing one to three hidden layers was employed and combined with logistic regression models. This study could show that deep learning approaches are able to provide tools for distinguishing treatment responders from nonresponders prior to antidepressant treatment. ${ }^{168}$ Drug discovery is another field for deep learning application, as it enables bioactivity predictions, synthesis prediction, biological image analysis, and de novo molecular design. ${ }^{166}$

In conclusion, machine learning offers a framework of tools to enable clinical prediction on an individual level. Combining genetic data with blood-based biomarkers, behavior and clinical factors pattern learning algorithms may identify disease-specific biological aspects that help to stratify disease, allocate patient subgroups to specific treatment options, and to identify subjects at risk or within a prodromal state. In this way, using concepts of artificial intelligence, precision medicine will provide specific treatment options or preventive strategies tailored to the individual person, across the common mental disease classifications.

\section{Disclosure}

The author reports no conflicts of interest in this work.

\section{References}

1. Kessler RC, Aguilar-Gaxiola S, Alonso J, et al. The global burden of mental disorders: an update from the WHO World Mental Health (WMH) surveys. Epidemiol Psychiatr Soc. 2009;18(1):23-33.

2. Wittchen HU, Jacobi F, Rehm J, et al. The size and burden of mental disorders and other disorders of the brain in Europe 2010. Eur Neuropsychopharmacol. 2011;21(9):655-679.

3. Wittchen HU, Jacobi F. Size and burden of mental disorders in Europea critical review and appraisal of 27 studies. Eur Neuropsychopharmacol. 2005;15(4):357-376.
4. Institute of Medicine (US) Committee on Pathophysiology and Prevention of Adolescent and Adult Suicide. Reducing Suicide: A National Imperative. Goldsmith SK, Pellmar TC, Kleinman AM, Bunney WE, editors. Washington (DC): National Academies Press (US);

5. Collins PY, Patel V, Joestl SS, et al. Grand challenges in global mental health. Nature. 2011;475(7354):27-30.

6. Stephan KE, Bach DR, Fletcher PC, et al. Charting the landscape of priority problems in psychiatry, part 1: classification and diagnosis. Lancet Psychiatry. 2016;3(1):77-83.

7. Cuthbert BN, Insel TR. Toward the future of psychiatric diagnosis: the seven pillars of RDoC. BMC Med. 2013;11(1):126.

8. Insel T, Cuthbert B, Garvey M, et al. Research domain criteria (RDoC): toward a new classification framework for research on mental disorders. Am J Psychiatry. 2010;167(7):748-751.

9. Mcmahon FJ. Prediction of treatment outcomes in psychiatry - where do we stand? Dialogues Clin Neurosci. 2014;16(4):455-464.

10. Collins FS, Varmus H. A new initiative on precision medicine. $N$ Engl J Med Overseas Ed. 2015;372(9):793-795.

11. Jameson JL, Longo D. Precision medicine - personalized, problematic, and promising. N Engl J Med. 2015;372(23):2229-2234.

12. Perlis RH. Abandoning personalization to get to precision in the pharmacotherapy of depression. World Psychiatry. 2016;15(3): 228-235.

13. Holsboer F. How can we realize the promise of personalized antidepressant medicines? Nat Rev Neurosci. 2008;9(8):638-646.

14. Insel TR, Scolnick EM. Cure therapeutics and strategic prevention: raising the bar for mental health research. Mol Psychiatry. 2006;11(1):11-17.

15. Wium-Andersen IK, Vinberg M, Kessing LV, McIntyre RS. Personalized medicine in psychiatry. Nord J Psychiatry. 2017;71(1):12-19.

16. Topol EJ. Individualized medicine from prewomb to tomb. Cell. 2014;157(1):241-253.

17. Sullivan PF, Agrawal A, Bulik CM, et al. Psychiatric genomics: an update and an agenda. Am J Psychiatry. 2018;175(1):15-27.

18. Sullivan PF, Daly MJ, O’Donovan M. Genetic architectures of psychiatric disorders: the emerging picture and its implications. Nat Rev Genet. 2012;13(8):537-551.

19. Smoller JW, Andreassen OA, Edenberg HJ, Faraone SV, Glatt SJ, Kendler KS. Psychiatric genetics and the structure of psychopathology. Mol Psychiatry. Epub 2018 Jan 9.

20. Maher B. Personal genomes: the case of the missing heritability. Nature. 2008;456(7218):18-21.

21. Corvin A, Craddock N, Sullivan PF. Genome-wide association studies: a primer. Psychol Med. 2010;40(7):1063-1077.

22. Altshuler D, Daly M. Guilt beyond a reasonable doubt. Nat Genet. 2007;39(7):813-815.

23. Mccarthy MI, Abecasis GR, Cardon LR, et al. Genome-wide association studies for complex traits: consensus, uncertainty and challenges. Nat Rev Genet. 2008;9(5):356-369.

24. Major Depressive Disorder Working Group of the Psychiatric GWAS Consortium, Ripke S, Wray NR, et al. A mega-analysis of genomewide association studies for major depressive disorder. Mol Psychiatry. 2013;18(4):497-511.

25. Hek K, Demirkan A, Lahti J, et al. A genome-wide association study of depressive symptoms. Biol Psychiatry. 2013;73(7):667-678.

26. Hyde CL, Nagle MW, Tian C, et al. Identification of 15 genetic loci associated with risk of major depression in individuals of European descent. Nat Genet. 2016;48(9):1031-1036.

27. Wray NR, Ripke S, Mattheisen M, et al. Genome-wide association analyses identify 44 risk variants and refine the genetic architecture of major depression. Nat Genet. 2018;50(5):668-681.

28. Ripke S, Sanders AR, Kendler KS, Schizophrenia Psychiatric Genome-Wide Association Study (GWAS) Consortium. Genome-wide association study identifies five new schizophrenia loci. Nat Genet. 2011;43(10):969-976.

29. Schizophrenia Working Group of the Psychiatric Genomics Consortium. Biological insights from 108 schizophrenia-associated genetic loci. Nature. 2014;511(7510):421-427. 
30. Breen G, Li Q, Roth BL, et al. Translating genome-wide association findings into new therapeutics for psychiatry. Nat Neurosci. 2016;19(11):1392-1396.

31. Nelson MR, Tipney H, Painter JL, et al. The support of human genetic evidence for approved drug indications. Nat Genet. 2015;47(8): 856-860.

32. Mangravite LM, Medina MW, Cui J, et al. Combined influence of $L D L R$ and $H M G C R$ sequence variation on lipid-lowering response to simvastatin. Arterioscler Thromb Vasc Biol. 2010;30(7):1485-1492.

33. Kathiresan S, Willer CJ, Peloso GM, et al. Common variants at 30 loci contribute to polygenic dyslipidemia. Nat Genet. 2009;41(1):56-65.

34. Brainstorm Consortium, Anttila V, Bulik-Sullivan B, et al. Analysis of shared heritability in common disorders of the brain. Science. 2018;360(6395):eaap8757.

35. Gandal MJ, Haney JR, Parikshak NN, et al. Shared molecular neuropathology across major psychiatric disorders parallels polygenic overlap. Science. 2018;359(6376):693-697.

36. Klengel T, Binder EB. Epigenetics of stress-related psychiatric disorders and gene $\times$ environment interactions. Neuron. 2015;86(6):1343-1357.

37. Binder EB. Dissecting the molecular mechanisms of gene $\times$ environment interactions: implications for diagnosis and treatment of stressrelated psychiatric disorders. Eur J Psychotraumatol. 2017;8(Suppl 5):1412745.

38. Kendler KS, Davis CG, Kessler RC. The familial aggregation of common psychiatric and substance use disorders in the National Comorbidity Survey: a family history study. Br J Psychiatry. 1997;170(6): 541-548.

39. Kessler RC, Davis CG, Kendler KS. Childhood adversity and adult psychiatric disorder in the US National Comorbidity Survey. Psychol Med. 1997;27(5):1101-1119.

40. Heim C, Nemeroff CB. The role of childhood trauma in the neurobiology of mood and anxiety disorders: preclinical and clinical studies. Biol Psychiatry. 2001;49(12):1023-1039.

41. Matosin N, Halldorsdottir T, Binder EB. Understanding the molecular mechanisms underpinning gene by environment interactions in psychiatric disorders: The FKBP5 Model. Biol Psychiatry. 2018;83(10):821-830.

42. Danese A, J Lewis S. Psychoneuroimmunology of early-life stress: the hidden wounds of childhood trauma? Neuropsychopharmacology. 2017;42(1):99-114.

43. Kuhlman KR, Chiang JJ, Horn S, Bower JE. Developmental psychoneuroendocrine and psychoneuroimmune pathways from childhood adversity to disease. Neurosci Biobehav Rev. 2017;80:166-184.

44. Nusslock R, Miller GE. Early-life adversity and physical and emotional health across the lifespan: a neuroimmune network hypothesis. Biol Psychiatry. 2016;80(1):23-32.

45. Danese A, Pariante CM, Caspi A, Taylor A, Poulton R. Childhood maltreatment predicts adult inflammation in a life-course study. Proc Natl Acad Sci U S A. 2007;104(4):1319-1324.

46. Kirschbaum C, Pirke KM, Hellhammer DH. The 'Trier Social Stress Test' - a tool for investigating psychobiological stress responses in a laboratory setting. Neuropsychobiology. 1993;28(1-2):76-81.

47. Pace TW, Mletzko TC, Alagbe O, et al. Increased stress-induced inflammatory responses in male patients with major depression and increased early life stress. Am J Psychiatry. 2006;163(9):1630-1633.

48. Carpenter LL, Gawuga CE, Tyrka AR, Lee JK, Anderson GM, Price LH. Association between plasma IL-6 response to acute stress and early-life adversity in healthy adults. Neuropsychopharmacology. 2010;35(13):2617-2623.

49. Leistner C, Menke A. How to measure glucocorticoid receptor's sensitivity in patients with stress-related psychiatric disorders. Psychoneuroendocrinology. 2018;91:235-260.

50. Menke A, Lehrieder D, Fietz J, et al. Childhood trauma dependent anxious depression sensitizes HPA axis function. Psychoneuroendocrinology. 2018;98:22-29.

51. Uher R, Tansey KE, Dew T, et al. An inflammatory biomarker as a differential predictor of outcome of depression treatment with escitalopram and nortriptyline. Am J Psychiatry. 2014;171(12):1278-1286.
52. Raison CL, Rutherford RE, Woolwine BJ, et al. A randomized controlled trial of the tumor necrosis factor antagonist infliximab for treatment-resistant depression: the role of baseline inflammatory biomarkers. JAMA Psychiatry. 2013;70(1):31-41.

53. Köhler O, Benros ME, Nordentoft M, et al. Effect of anti-inflammatory treatment on depression, depressive symptoms, and adverse effects a systematic review and meta-analysis of randomized clinical trials. JAMA Psychiatry. 2014;71(12):1381-1391.

54. Kappelmann N, Lewis G, Dantzer R, Jones PB, Khandaker GM. Antidepressant activity of anti-cytokine treatment: a systematic review and meta-analysis of clinical trials of chronic inflammatory conditions. Mol Psychiatry. 2018;23(2):335-343.

55. de Kloet ER, Joëls M, Holsboer F. Stress and the brain: from adaptation to disease. Nat Rev Neurosci. 2005;6(6):463-475.

56. Menke A, Binder EB. Epigenetic alterations in depression and antidepressant treatment. Dialogues Clin Neurosci. 2014;16(3):395-404

57. Menke A, Klengel T, Binder EB. Epigenetics, depression and antidepressant treatment. Curr Pharm Des. 2012;18(36):5879-5889.

58. Dwivedi Y. Emerging role of microRNAs in major depressive disorder: diagnosis and therapeutic implications. Dialogues Clin Neurosci. 2014;16(1):43-61.

59. Geaghan M, Cairns MJ. MicroRNA and posttranscriptional dysregulation in psychiatry. Biol Psychiatry. 2015;78(4):231-239.

60. Binder EB. The role of FKBP5, a co-chaperone of the glucocorticoid receptor in the pathogenesis and therapy of affective and anxiety disorders. Psychoneuroendocrinology. 2009;34(Suppl 1):S186-S195.

61. Binder EB, Salyakina D, Lichtner P, et al. Polymorphisms in FKBP5 are associated with increased recurrence of depressive episodes and rapid response to antidepressant treatment. Nat Genet. 2004;36(12): 1319-1325.

62. Menke A, Klengel T, Rubel J, et al. Genetic variation in FKBP5 associated with the extent of stress hormone dysregulation in major depression. Genes Brain Behav. 2013;12(3):289-296.

63. Klengel T, Mehta D, Anacker C, et al. Allele-specific FKBP5 DNA demethylation mediates gene-childhood trauma interactions. Nat Neurosci. 2013;16(1):33-41.

64. Grabe HJ, Wittfeld K, Van der Auwera S, et al. Effect of the interaction between childhood abuse and rs1360780 of the FKBP5 gene on gray matter volume in a general population sample. Hum Brain Mapp. 2016;37(4):1602-1613.

65. Han KM, Won E, Sim Y, et al. Influence of FKBP5 polymorphism and DNA methylation on structural changes of the brain in major depressive disorder. Sci Rep. 2017;7(1):42621.

66. Tozzi L, Farrell C, Booij L, et al. Epigenetic changes of FKBP5 as a link connecting genetic and environmental risk factors with structural and functional brain changes in major depression. Neuropsychopharmacology. 2018;43(5):1138-1145.

67. Lovallo WR, Enoch MA, Acheson A, et al. Early-life adversity interacts with FKBP5 genotypes: altered working memory and cardiac stress reactivity in the Oklahoma Family Health Patterns Project. Neuropsychopharmacology. 2016;41(7):1724-1732.

68. Gopalakrishnan R, Kozany C, Gaali S, et al. Evaluation of synthetic FK506 analogues as ligands for the FK506-binding proteins 51 and 52. J Med Chem. 2012;55(9):4114-4122.

69. Gopalakrishnan R, Kozany C, Wang Y, et al. Exploration of pipecolate sulfonamides as binders of the FK506-binding proteins 51 and 52. $J$ Med Chem. 2012;55(9):4123-4131.

70. Menke A, Arloth J, Best J, et al. Time-dependent effects of dexamethasone plasma concentrations on glucocorticoid receptor challenge tests. Psychoneuroendocrinology. 2016;69:161-171.

71. Menke A, Arloth J, Gerber M, et al. Dexamethasone stimulated gene expression in peripheral blood indicates glucocorticoid-receptor hypersensitivity in job-related exhaustion. Psychoneuroendocrinology. 2014;44:35-46.

72. Menke A, Arloth J, Pütz B, et al. Dexamethasone stimulated gene expression in peripheral blood is a sensitive marker for glucocorticoid receptor resistance in depressed patients. Neuropsychopharmacology. 2012;37(6):1455-1464 
73. Cohen S, Janicki-Deverts D, Miller GE. Psychological stress and disease. JAMA. 2007;298(14):1685-1687.

74. Wilbert-Lampen U, Leistner D, Greven S, et al. Cardiovascular events during World Cup Soccer. N Engl J Med Overseas Ed. 2008;358(5): 475-483.

75. Arango C, Díaz-Caneja CM, McGorry PD, et al. Preventive strategies for mental health. Lancet Psychiatry. 2018;5(7):591-604.

76. van den Bosch M, Ode Sang $\AA$. Urban natural environments as naturebased solutions for improved public health - a systematic review of reviews. Environ Res. 2017;158:373-384.

77. Morita E, Fukuda S, Nagano J, et al. Psychological effects of forest environments on healthy adults: Shinrin-yoku (forest-air bathing, walking) as a possible method of stress reduction. Public Health. 2007;121(1):54-63.

78. Ideno Y, Hayashi K, Abe Y, et al. Blood pressure-lowering effect of Shinrin-yoku (Forest bathing): a systematic review and meta-analysis. BMC Complement Altern Med. 2017;17(1):409.

79. Song C, Ikei H, Miyazaki Y. Physiological effects of nature therapy: a review of the research in Japan. Int J Environ Res Public Health. 2016;13(8):781.

80. Jacka FN, Mykletun A, Berk M. Moving towards a population health approach to the primary prevention of common mental disorders. $B M C$ Med. 2012;10(1):149.

81. Jacka FN, Pasco JA, Mykletun A, et al. Association of Western and traditional diets with depression and anxiety in women. Am J Psychiatry. 2010;167(3):305-311.

82. Lai JS, Hiles S, Bisquera A, Hure AJ, Mcevoy M, Attia J. A systematic review and meta-analysis of dietary patterns and depression in community-dwelling adults. Am J Clin Nutr. 2014;99(1):181-197.

83. O'Neil A, Quirk SE, Housden S, et al. Relationship between diet and mental health in children and adolescents: a systematic review. $\mathrm{Am} \mathrm{J}$ Public Health. 2014;104(10): e31-e42.

84. Sarris J, Logan AC, Akbaraly TN, et al. Nutritional medicine as mainstream in psychiatry. Lancet Psychiatry. 2015;2(3):271-274.

85. Saunders EF, Ramsden CE, Sherazy MS, Gelenberg AJ, Davis JM, Rapoport SI. Reconsidering dietary polyunsaturated fatty acids in bipolar disorder: a translational picture. $J$ Clin Psychiatry. 2016;77(10):e1342-e1347.

86. Dickerson F, Stallings C, Origoni A, Vaughan C, Khushalani S, Yolken R. Markers of gluten sensitivity in acute mania: a longitudinal study. Psychiatry Res. 2012;196(1):68-71.

87. Brown NC, Andreazza AC, Young LT. An updated meta-analysis of oxidative stress markers in bipolar disorder. Psychiatry Res. 2014;218(1-2):61-68.

88. Severance EG, Tveiten D, Lindström LH, Yolken RH, Reichelt KL. The gut microbiota and the emergence of autoimmunity: relevance to major psychiatric disorders. Curr Pharm Des. 2016;22(40):6076-6086.

89. Willett WC, Sacks F, Trichopoulou A, et al. Mediterranean diet pyramid: a cultural model for healthy eating. Am J Clin Nutr. 1995;61(6 Suppl):S1402-S1406.

90. Estruch R, Ros E, Salas-Salvadó J, et al. Primary prevention of cardiovascular disease with a Mediterranean diet supplemented with extra-virgin olive oil or nuts. $N$ Engl $J$ Med Overseas Ed. 2018; 378(25):e34.

91. Sofi F, Abbate R, Gensini GF, Casini A. Accruing evidence on benefits of adherence to the Mediterranean diet on health: an updated systematic review and meta-analysis. Am J Clin Nutr. 2010;92(5): 1189-1196.

92. Psaltopoulou T, Sergentanis TN, Panagiotakos DB, Sergentanis IN, Kosti R, Scarmeas N. Mediterranean diet, stroke, cognitive impairment, and depression: a meta-analysis. Ann Neurol. 2013;74(4):580-591.

93. Grosso G, Micek A, Marventano S, et al. Dietary n-3 PUFA, fish consumption and depression: a systematic review and meta-analysis of observational studies. J Affect Disord. 2016;205:269-281.

94. Mocking RJ, Harmsen I, Assies J, Koeter MW, Ruhé HG, Schene AH. Meta-analysis and meta-regression of omega-3 polyunsaturated fatty acid supplementation for major depressive disorder. Transl Psychiatry. 2016;6(3):e756.
95. Jacka FN, O'Neil A, Opie R, et al. A randomised controlled trial of dietary improvement for adults with major depression (the 'SMILES' trial). BMC Med. 2017;15(1):23.

96. Khambadkone SG, Cordner ZA, Dickerson F, et al. Nitrated meat products are associated with mania in humans and altered behavior and brain gene expression in rats. Mol Psychiatry. Epub 2018 Jul 18.

97. Hallgren M, Herring MP, Owen N, et al. Exercise, physical activity, and sedentary behavior in the treatment of depression: broadening the scientific perspectives and clinical opportunities. Front Psychiatry. 2016;7(1):36.

98. Pedersen BK, Saltin B. Exercise as medicine - evidence for prescribing exercise as therapy in 26 different chronic diseases. Scand J Med Sci Sports. 2015;25(Suppl 3):1-72.

99. Manji HK, Moore GJ, Chen G. Clinical and preclinical evidence for the neurotrophic effects of mood stabilizers: implications for the pathophysiology and treatment of manic-depressive illness. Biol Psychiatry. 2000;48(8):740-754.

100. Pedersen BK, Febbraio MA. Muscle as an endocrine organ: focus on muscle-derived interleukin-6. Physiol Rev. 2008;88(4): 1379-1406.

101. Pedersen BK, Pedersen M, Krabbe KS, Bruunsgaard H, Matthews VB, Febbraio MA. Role of exercise-induced brain-derived neurotrophic factor production in the regulation of energy homeostasis in mammals. Exp Physiol. 2009;94(12):1153-1160.

102. Roshanaei-Moghaddam B, Katon WJ, Russo J. The longitudinal effects of depression on physical activity. Gen Hosp Psychiatry. 2009;31(4):306-315.

103. Conn VS. Depressive symptom outcomes of physical activity interventions: meta-analysis findings. Ann Behav Med. 2010;39(2):128-138.

104. Dunn AL, Trivedi MH, Kampert JB, Clark CG, Chambliss HO. Exercise treatment for depression: efficacy and dose response. Am J Prev Med. 2005;28(1):1-8.

105. Bartley CA, Hay M, Bloch MH. Meta-analysis: aerobic exercise for the treatment of anxiety disorders. Prog Neuropsychopharmacol Biol Psychiatry. 2013;45:34-39.

106. Firth J, Cotter J, Elliott R, French P, Yung AR. A systematic review and meta-analysis of exercise interventions in schizophrenia patients. Psychol Med. 2015;45(7):1343-1361.

107. Forbes D, Forbes SC, Blake CM, Thiessen EJ, Forbes S. Exercise programs for people with dementia. Cochrane Database Syst Rev. 2015;(4):CD006489.

108. Busch Y, Menke A. Blood-based biomarkers predicting response to antidepressants. J Neural Transm. Epub 2018 Jan 27.

109. Ising M, Lucae S, Binder EB, et al. A genomewide association study points to multiple loci that predict antidepressant drug treatment outcome in depression. Arch Gen Psychiatry. 2009;66(9):966-975.

110. Tansey KE, Guipponi M, Hu X, et al. Contribution of common genetic variants to antidepressant response. Biol Psychiatry. 2013;73(7):679-682.

111. Arranz MJ, Rivera M, Munro JC. Pharmacogenetics of response to antipsychotics in patients with schizophrenia. CNS Drugs. 2011;25(11):933-969.

112. Fabbri C, Porcelli S, Serretti A. From pharmacogenetics to pharmacogenomics: the way toward the personalization of antidepressant treatment. Can J Psychiatry. 2014;59(2):62-75.

113. Brandl EJ, Kennedy JL, Müller DJ. Pharmacogenetics of antipsychotics. Can J Psychiatry. 2014;59(2):76-88.

114. Serretti A. The present and future of precision medicine in psychiatry: focus on clinical psychopharmacology of antidepressants. Clin Psychopharmacol Neurosci. 2018;16(1):1-6.

115. Fabbri C, Hosak L, Mössner R, et al. Consensus paper of the WFSBP Task Force on Genetics: genetics, epigenetics and gene expression markers of major depressive disorder and antidepressant response. World J Biol Psychiatry. 2017;18(1):5-28.

116. Bousman CA, Hopwood M. Commercial pharmacogeneticbased decision-support tools in psychiatry. Lancet Psychiatry. 2016;3(6):585-590. 
117. Bousman CA, Forbes M, Jayaram M, et al. Antidepressant prescribing in the precision medicine era: a prescriber's primer on pharmacogenetic tools. BMC Psychiatry. 2017;17(1):60.

118. Nassan M, Nicholson WT, Elliott MA, Rohrer Vitek CR, Black JL, Frye MA. Pharmacokinetic pharmacogenetic prescribing guidelines for antidepressants: a template for psychiatric precision medicine. Mayo Clin Proc. 2016;91(7):897-907.

119. Müller DJ, Kekin I, Kao AC, Brandl EJ. Towards the implementation of CYP2D6 and CYP2C19 genotypes in clinical practice: update and report from a pharmacogenetic service clinic. Int Rev Psychiatry. 2013;25(5):554-571.

120. Relling MV, Klein TE. CPIC: Clinical Pharmacogenetics Implementation Consortium of the Pharmacogenomics Research Network. Clin Pharmacol Ther. 2011;89(3):464-467.

121. Breitenstein B, Brückl TM, Ising M, Müller-Myhsok B, Holsboer F, Czamara D. ABCB1 gene variants and antidepressant treatment outcome: a meta-analysis. Am J Med Genet B Neuropsychiatr Genet. 2015;168B(4):274-283.

122. Uhr M, Tontsch A, Namendorf C, et al. Polymorphisms in the drug transporter gene $\mathrm{ABCB} 1$ predict antidepressant treatment response in depression. Neuron. 2008;57(2):203-209.

123. Porcelli S, Fabbri C, Serretti A. Meta-analysis of serotonin transporter gene promoter polymorphism (5-HTTLPR) association with antidepressant efficacy. Eur Neuropsychopharmacol. 2012;22(4): 239-258.

124. Meyer JH, Kapur S, Eisfeld B, et al. The effect of paroxetine on 5-HT(2A) receptors in depression: an [(18)F]setoperone PET imaging study. Am J Psychiatry. 2001;158(1):78-85.

125. Pandey DK, Mahesh R, Kumar AA, Rao VS, Arjun M, Rajkumar R. A novel 5-HT(2A) receptor antagonist exhibits antidepressant-like effects in a battery of rodent behavioural assays: approaching early-onset antidepressants. Pharmacol Biochem Behav. 2010;94(3):363-373.

126. Winner JG, Dechairo B. Combinatorial versus individual gene pharmacogenomic testing in mental health: a perspective on context and implications on clinical utility. Yale J Biol Med. 2015;88(4): 375-382.

127. Berm EJ, Looff M, Wilffert B, et al. Economic evaluations of pharmacogenetic and pharmacogenomic screening tests: a systematic review. Second update of the literature. PLoS One. 2016;11(1):e0146262.

128. Yu S-H, Liu S-K, Lin K-M. Psychopharmacology across cultures. In Bhugra D, Bhui K, editors. Textbook of Cultural Psychiatry. 1st ed. Cambridge, UK: Cambridge University Press; 2007:402-413.

129. Menke A. Gene expression: biomarker of antidepressant therapy? Int Rev Psychiatry. 2013;25(5):579-591.

130. Gerhold DL, Jensen RV, Gullans SR. Better therapeutics through microarrays. Nat Genet. 2002;32(Suppl):547-551.

131. Dirven BCJ, Homberg JR, Kozicz T, Henckens M. Epigenetic programming of the neuroendocrine stress response by adult life stress. $J \mathrm{Mol}$ Endocrinol. 2017;59(1):R11-R31.

132. Reinbold CS, Forstner AJ, Hecker J, et al. Analysis of the influence of microRNAs in lithium response in bipolar disorder. Front Psychiatry. 2018;9:207.

133. Lopez JP, Kos A, Turecki G. Major depression and its treatment: microRNAs as peripheral biomarkers of diagnosis and treatment response. Curr Opin Psychiatry. 2018;31(1):7-16.

134. Mehta D, Gonik M, Klengel T, et al. Using polymorphisms in FKBP5 to define biologically distinct subtypes of posttraumatic stress disorder: evidence from endocrine and gene expression studies. Arch Gen Psychiatry. 2011;68(9):901-910.

135. Arloth J, Bogdan R, Weber P, et al. Genetic differences in the immediate transcriptome response to stress predict risk-related brain function and psychiatric disorders. Neuron. 2015;86(5):1189-1202.

136. Zannas AS, Arloth J, Carrillo-Roa T, et al. Lifetime stress accelerates epigenetic aging in an urban, African American cohort: relevance of glucocorticoid signaling. Genome Biol. 2015;16:266.

137. Shickel B, Tighe PJ, Bihorac A, Rashidi P. Deep EHR: a survey of recent advances in deep learning techniques for electronic health record (EHR) analysis. IEEE J Biomed Health Inform. 2018;22(5):1589-1604.
138. Pham T, Tran T, Phung D, Venkatesh S. Predicting healthcare trajectories from medical records: a deep learning approach. J Biomed Inform. 2017;69:218-229.

139. Tran T, Kavuluru R. Predicting mental conditions based on "history of present illness" in psychiatric notes with deep neural networks. $J$ Biomed Inform. 2017;75S:S138-S148.

140. Rosenstein M, Foltz PW, Delisi LE, Elvevåg B. Language as a biomarker in those at high-risk for psychosis. Schizophr Res. 2015;165(2-3): 249-250.

141. Ebner-Priemer UW, Trull TJ. Ecological momentary assessment of mood disorders and mood dysregulation. Psychol Assess. 2009;21(4):463-475

142. Kingslake J, Dias R, Dawson GR, et al. The effects of using the PReDicT test to guide the antidepressant treatment of depressed patients: study protocol for a randomised controlled trial. Trials. 2017;18(1):558.

143. Surguladze SA, Young AW, Senior C, Brébion G, Travis MJ, Phillips ML. Recognition accuracy and response bias to happy and sad facial expressions in patients with major depression. Neuropsychology. 2004;18(2):212-218

144. Harmer CJ, O'Sullivan U, Favaron E, et al. Effect of acute antidepressant administration on negative affective bias in depressed patients. Am J Psychiatry. 2009;166(10):1178-1184.

145. Dawson GR, Dourish C, Kingslake J, Harmer C, Goodwin G, Browning $\mathrm{M}$. A precision medicine approach to antidepressant treatment in depression. Eur Neuropsychopharmacol. 2015;25:S441.

146. Gustavsson A, Svensson M, Jacobi F, et al. Cost of disorders of the brain in Europe 2010. Eur Neuropsychopharmacol. 2011;21(10):718-779.

147. Hunger SP, Lu X, Devidas M, et al. Improved survival for children and adolescents with acute lymphoblastic leukemia between 1990 and 2005: a report from the children's oncology group. JClin Oncol. 2012;30(14): 1663-1669.

148. Kessler RC, Demler O, Frank RG, et al. Prevalence and treatment of mental disorders, 1990 to 2003. N Engl J Med. 2005;352(24):2515-2523.

149. Wong EH, Yocca F, Smith MA, Lee CM. Challenges and opportunities for drug discovery in psychiatric disorders: the drug hunters' perspective. Int J Neuropsychopharmacol. 2010;13(9):1269-1284.

150. Hofmann SG, Asnaani A, Vonk IJ, Sawyer AT, Fang A. The efficacy of cognitive behavioral therapy: a review of meta-analyses. Cognit Ther Res. 2012;36(5):427-440.

151. Gabrieli JDE, Ghosh SS, Whitfield-Gabrieli S. Prediction as a humanitarian and pragmatic contribution from human cognitive neuroscience. Neuron. 2015;85(1):11-26.

152. Cross-Disorder Group of the Psychiatric Genomics Consortium. Identification of risk loci with shared effects on five major psychiatric disorders: a genome-wide analysis. Lancet. 2013;381(9875):1371-1379.

153. Ehrenreich H, Mitjans M, Van der Auwera S, et al. OTTO: a new strategy to extract mental disease-relevant combinations of GWAS hits from individuals. Mol Psychiatry. 2018;23(2):476-486.

154. Wolfers T, Buitelaar JK, Beckmann CF, Franke B, Marquand AF. From estimating activation locality to predicting disorder: a review of pattern recognition for neuroimaging-based psychiatric diagnostics. Neurosci Biobehav Rev. 2015;57:328-349.

155. Chan MK, Gottschalk MG, Haenisch F, et al. Applications of bloodbased protein biomarker strategies in the study of psychiatric disorders. Prog Neurobiol. 2014;122:45-72.

156. Fu CH, Costafreda SG. Neuroimaging-based biomarkers in psychiatry: clinical opportunities of a paradigm shift. Can J Psychiatry. 2013;58(9):499-508.

157. Hofmann-Apitius M, Ball G, Gebel S, et al. Bioinformatics mining and modeling methods for the identification of disease mechanisms in neurodegenerative disorders. Int J Mol Sci. 2015;16(12):29179-29206.

158. Savitz JB, Rauch SL, Drevets WC. Clinical application of brain imaging for the diagnosis of mood disorders: the current state of play. Mol Psychiatry. 2013;18(5):528-539.

159. Scarr E, Millan MJ, Bahn S, et al. Biomarkers for Psychiatry: The Journey from Fantasy to Fact, a Report of the 2013 CINP Think Tank. Int J Neuropsychopharmacol. 2015;18(10):pyv042. 
160. Veronese E, Castellani U, Peruzzo D, Bellani M, Brambilla P. Machine learning approaches: from theory to application in schizophrenia. Comput Math Methods Med. 2013;2013:867924.

161. Hahn T, Nierenberg AA, Whitfield-Gabrieli S. Predictive analytics in mental health: applications, guidelines, challenges and perspectives. Mol Psychiatry. 2017;22(1):37-43.

162. Bzdok D, Meyer-Lindenberg A. Machine learning for precision psychiatry: opportunities and challenges. Biol Psychiatry Cogn Neurosci Neuroimaging. 2018;3(3):223-230.

163. Woo CW, Chang LJ, Lindquist MA, Wager TD. Building better biomarkers: brain models in translational neuroimaging. Nat Neurosci. 2017;20(3):365-377.

164. Esteva A, Kuprel B, Novoa RA, et al. Dermatologist-level classification of skin cancer with deep neural networks. Nature. 2017;542(7639):115-118.
165. Kessler RC, van Loo HM, Wardenaar KJ, et al. Testing a machinelearning algorithm to predict the persistence and severity of major depressive disorder from baseline self-reports. Mol Psychiatry. 2016;21(10):1366-1371.

166. Chen H, Engkvist O, Wang Y, Olivecrona M, Blaschke T. The rise of deep learning in drug discovery. Drug Discov Today. 2018;23(6):1241-1250.

167. Torkamani A, Andersen KG, Steinhubl SR, Topol EJ. High-definition medicine. Cell. 2017;170(5):828-843.

168. Lin E, Kuo PH, Liu YL, Yu Y, Yang AC, Tsai SJ. A deep learning approach for predicting antidepressant response in major depression using clinical and genetic biomarkers. Front Psychiatry. 2018;9(290):290.

\section{Publish your work in this journal}

Pharmacogenomics and Personalized Medicine is an international, peerreviewed, open access journal characterizing the influence of genotype on pharmacology leading to the development of personalized treatment programs and individualized drug selection for improved safety, efficacy and sustainability. This journal is indexed on the American Chemical
Society's Chemical Abstracts Service (CAS). The manuscript management system is completely online and includes a very quick and fair peer-review system, which is all easy to use. Visit http://www.dovepress. com/testimonials.php to read real quotes from published authors. 